\title{
Território e trabalho: análise geoeconômica com base em trajetórias camponesas
}

\section{Territory and work: a geoeconomical analysys based on peasant trajectories}

Karen de Nazareth Santos Nogueira - Mestre em Planejamento do Desenvolvimento pelo Núcleo de Altos Estudos Amazônicos (NAEA/UFPA). Analista em Geoprocessamento no Instituto de Pesquisas Espaciais, Centro Regional da Amazônia (INPE/CRA). E-mail: kns.nogueira@hotmail.com

Francisco de Assis Costa - Doutor em Economia pela Freie Universität Berlin, professor titular da Universidade Federal do Pará, no Programa de Pós-Graduação em Desenvolvimento Sustentável do Trópico Úmido do NAEA e do Programa de Pós-Graduação em Economia da Faculdade de Economia. E-mail: francisco_de_assis_costa@yahoo.com.br

Marcos Adami - Doutor em Sensoriamento Remoto pelo Instituto Nacional de Pesquisas Espaciais. Pesquisador do Instituto Nacional de Pesquisas Espaciais no Centro Regional da Amazônia (INPE/CRA). E-mail: marcos.adami@inpe.br

\section{Resumo}

A pesquisa tem como foco a análise da configuração territorial rural do município de Mocajuba, que se localiza na região do Baixo-Tocantins. Com base na teoria de trajetórias tecnológicas rurais para a Amazônia, foi estudada a especificidade da economia camponesa, particularmente seu segmento baseado no agroextrativismo. Com isso objetiva-se indicar os tipos e percentuais de uso e cobertura da terra que os agentes da trajetória camponesa T2, empregam no território. Por meio do processamento de dados de satélite em associação a dados econométricos, concluise que os territórios onde se encontram as trajetórias agroextrativistas, apresentam níveis de conservação florestal consideráveis, se comparados a outras trajetórias. Pode-se afirmar ainda que o trabalho é parâmetro fundamental de alocação espacial, por expressar-se em extensão, mobilidade e padrões de alocação, bem como o território, que neste contexto torna-se o atributo essencial de fundamentação do trabalho.

\section{Palavras-chave}

Território. Trabalho. Trajetória Agroextrativista. Geoprocessamento.

\begin{abstract}
The research aims the analysis of the rural landed set of Mocajuba's county, which is located in Baixo-Tocantins region. Based in the theory of rural technological paths for the Amazon, it was studied the specificity of the peasant economy, particularly its segment based on the agro-extractivism. Therefore, objective is to indicate the types and percentages of land use and land cover that agents of peasant trajectory T2, employ the territory Through the processing of satellite data associated to econometric data. it is concluded that the territories where the agroextractivist trajectories, present considerable forest conservation levels, compared to other paths. One can also say that the work is fundamental parameter space allocation, to express in length, mobility and allocation patterns, and the territory, which in this context becomes the essential attribute of work reasons.
\end{abstract}

\section{Keywords}

Territory. Work. Agro-extractive Path. Geoprocessing. 


\section{INTRODUÇÃO}

A pesquisa tem como foco a análise da configuração territorial rural do município de Mocajuba, que se localiza na região do Baixo-Tocantins. Com base na teoria de trajetórias tecnológicas rurais para a Amazônia, foi estudada a especificidade da economia camponesa, particularmente seu segmento baseado no agroextrativismo.

O rural mocajubense é dominantemente camponês. Com base na noção de trajetórias, pretende-se estudar como a especificidade da economia camponesa, particularmente seu segmento baseado no agroextrativismo configura o território de Mocajuba. Esses agentes secularmente estabelecidos e com relações de produção e vivência muito bem delimitadas, são camponeses em uma acepção chayanoviana, cuja racionalidade é concretizada a partir dos padrões reprodutivos orientados pela satisfação das necessidades da família.

Por entendermos que a teoria de Chayanov (1974) tem aplicação aos múltiplos sistemas de produção amazônicos é que podemos dizer que a base produtiva destes camponeses se orienta em última instância por trajetórias tecnológicas, tal qual definidas por Costa (2009b) cuja base técnica está apoiada num conhecimento do bioma, de um manejo sobre o território. Esse campesinato ancestral fundou uma dinâmica ligada a processos estruturais que movimentam a economia da região a partir de uma lógica produtiva cujo domínio técnico da produção se dá por ativos específicos, cujas práticas de manejo pressupõem a manutenção do bioma. Com base em regras de convívio próprias, acordos tácitos e regras de manejo do recurso muito específicas marcam essa trajetória orientada para o agroextrativismo.

A dinâmica produtiva dessas territorialidades ancestrais na história da Amazônia vem sendo afetada nos últimos anos, de um lado, pelos movimentos de etnogênese de base camponesa; de outro, nas políticas de regularização fundiária nacional na escala compreendida por um mosaico de situações que tem como núcleo intervenções concretas: o estabelecimento de 4 projetos agroextrativistas (PAE da Ilha Grande de Conceição de Mocajuba ${ }^{1}$, PAE da Ilha Grande do Vizeu $^{2}$, PAE da Ilha de Angapijón ${ }^{3}$ PAE Ilha de Tauré ${ }^{4}$ ) e 1 território quilombola (TEQ 2ำ Distrito de Porto Grande ${ }^{5}$ ).

\footnotetext{
Portaria $\mathrm{n}^{\mathrm{0}} 187$, de 15 de dezembro de 2009.

Portaria $\mathrm{n}^{\mathrm{o}}$ 188, de 15 de dezembro de 2009.

Portaria no 186 , de 15 de dezembro de 2009.

Portaria n⿳⺈ 189, de 15 de dezembro de 2009.

Título outorgado pelo ITERPA, em 2 de dezembro de 2008.
} 
É especificamente desta economia em muito esquecido ou considerada como de segunda ordem que pretendermos dar conta na proposta em questão. Economia esta, secularmente, estabelecida e baseada na tradição indígena vem desenvolvendo sistemas econômicos baseados no manejo dos ecossistemas naturais e em cultivos capazes não apenas de coexistirem com ecossistemas naturais, como também de enriquecê-los.

A diversificação da produção nessa economia foi e só é possível graças ao desenvolvimento de tecnologias de manejo e cultivo, a exemplo da domesticação de vegetais como a macaxeira, base para produção da farinha, componente importante na dieta familiar. Também se criou tecnologia de utilização de outros produtos como o açaí, a bacaba, o buriti e a copaíba.

Tais formas produtivas, por se desenvolverem nas franjas do crescimento econômico capitalista, encontram no desinteresse político e na presença perversa do planejamento -voltado para atender a grandes demandas - a dificuldade na implementação de políticas que viabilizem o fortalecimento de tais economias com foco em suas potencialidades.

Esse modo de vida camponês está alicerçado sob relações identitárias e territoriais pré-estabelecidas e que ultrapassam os limites físicos propostos pelas áreas de regularização fundiária. Tais territorialidades fundamentam as relações produtivas e reprodutivas desses agentes que operam o bioma de forma específica.

Com isso, objetiva-se indicar os tipos e os percentuais de uso e cobertura da terra que os agentes da trajetória camponesa T2 empregam no território. Por meio do processamento de dados de satélite em associação com dados econométricos, conclui-se que resulta em níveis de conservação florestal consideráveis, se comparados a outras trajetórias. Dentro deste contexto, o trabalho é parâmetro fundamental de alocação espacial, por expressar-se em extensão, mobilidade e padrões de alocação, bem como o território, que neste contexto torna-se o atributo essencial de fundamentação do trabalho.

\section{TERRITÓRIO E TRABALHO}

Trabalho e território são categorias importantes do ponto de vista analítico, e carecem de integração do ponto de vista metodológico, haja vista que, por se inscreverem em temporalidades diferentes, apresentam dificuldade de articulação. O território tem inscrição em tempo longo e curto, já o trabalho inscreve-se em tempo curto, o que pode comprometer a análise dos processos sociais e institucionais. 
Trabalho e território são conceitos centrais em economia. Um movimento recente, sobretudo, na Economia vem buscando uma interpretação possível de articulação entre as duas categorias, haja vista que as duas noções são elementoschave para a compreensão da socialização dos indivíduos.

Para a Sociologia de Durkeim o trabalho se apresenta enquanto processo, como criador do vínculo social, enquanto que o território está ligado ao sentimento de pertencimento como constitutivo do reconhecimento identitário dos indivíduos.

De tais interpretações emerge a noção de territórios-atores no sentido de "pluralidade das temporalidades espacializadas" (BERTHELOT, 1996). Tal noção diverge da acepção geográfica de território, pois permite pensar o mesmo em dupla inscrição, pois expressa temporalidades sociais do trabalho e território.

A busca de soluções locais de desenvolvimento tem o território como vetor de diferenciação de economias internacionais e nacionais, o que tem efeito sobre a forma de organização do trabalho.

O território na geografia tradicional surge como alicerce do Estado "modo de existência do Estado no espaço" (ALLIĖS, 1980, p. 12), mas questões sobre a emergência do poder do Estado levam à transformação da noção móvel do espaço, a noção de território.

O Estado exerce poder sobre um território, e este expressa em última instância conflito de relações, o que lhe confere configuração e dinâmica especificas. Logo as instituições comprovam o ancoramento do território nas relações locais, o que confere a este inscrição em tempo longo, sob mediação do estado.

Por outro lado, os vínculos informais, as convenções e as regras reproduzidas em escala local oferecem suporte sobre a atividade de trabalho, por meio de códigos tácitos e explícitos, de formalidade e informalidade que dão o tom da dinâmica territorial do lugar. Tais arranjos referem-se a território em tempo curto, mais imediato.

\section{A MULTIDIMENSIONALIDADE DO TERRITÓRIO E A CENTRALIDADE DO TRABALHO NA SUA CONSTITUIÇÃO}

$\mathrm{Na}$ geografia a relação com o aspecto físico do território foi por longo tempo a base do exercício da vida em sociedade, sobretudo, a maneira como os indivíduos se relacionam e criam uma representação própria de espaço, está na origem e constituição dos territórios (AZAÏZ, 2004).

Economistas como Krugman (1998) vão além ao entender que o exercício de uma atividade econômica está profundamente ligado à funcionalidade de um 
dado lugar. Daí a importância no reconhecimento das redes na constituição de um sistema produtivo.

Na emergência desse debate, surge o interesse metodológico na dimensão meso, como aporte analítico ao entendimento de que a temporalidade permite distinguir as noções de território e espaço.

Prévot e Schapira (1997) foram precursores ao tratar do território como construção histórica que encontra seu princípio unificador nas práticas sociais do momento. Outros estudiosos da questão inserem nesse contexto a variável temporal dessas formas de desenvolvimento territorial. Ph Aydalot vai além e oferece complexa análise da implicação dessas formas de desenvolvimento em estruturas institucionais e socioeconômicas, em uma dada escala temporal.

De acordo com Bellet, Collettis e Yung (1993), o território é entendido como construção das práticas e das representações dos agentes econômicos, ou ainda como ator do desenvolvimento econômico. Portanto, o território ocupa lugar ativo por ser produtor de externalidades, ou seja, é uma estrutura ativa de desenvolvimento, estagnação e retrocesso. E as práticas sociais que se estabelecem em escala micro são a chave de sedimentação do território. "Portanto, o ponto de convergência entre o território e o trabalho reside na temporalidade, curta, que precisa da temporalidade longa do território para expressar-se plenamente" (AZAIS, 2004,p.38).

Diante do aqui exposto, pode-se dizer que a territorialidade permite ao trabalho e às formas variadas que adota tornar-se lugar privilegiado de construção do vínculo social, tendo no território a estruturação social do espaço, dinâmica, inscrita num tempo.

O esforço, sobretudo, dos economistas tem sido de compreender o desenvolvimento territorial sob a perspectiva da diferenciação dos territórios, no que se refere às esferas da produção e trabalho. Azaïs (2004) reforça a ideia de que desenvolvimento não se resume a desenvolvimento "top down" ou botton down". O processo é mais complexo, pois envolve influências estruturais aplicadas a escalas local e global.

Logo, do ponto de vista endógeno não se deve desconsiderar determinações de ordem macroeconômica ou microssocial, bem como, da perspectiva exógena não se pode negar a importância da estrutura socioeconômica e histórica, produto das instituições e dos homens que "fazem" o território e nele trabalham.

O território, dentro de uma lógica própria, tem capacidade de produzir e apoderar-se das externalidades e fazê-las render, sendo capaz portanto, de ser agente socialmente inovador. 
A territorialidade, entendida como processo de apropriação do espaço por um grupo, indivíduo ou organização, incorpora aspectos da relação entre os atores sociais e sua base natural de existência. Milton Santos (1996) via com clareza essa dimensão da vida social, entendendo a partir daí que as formas de operação do trabalho vivo (em fluxos) sobre esse fundamento, e os meios utilizados (diferentes estruturas e meios) obtidos por trabalho pretérito cristalizado (fixos), constituem a dimensão fundamental dos territórios.

Costa (2008) explicita como peculiaridade o bioma amazônico como objeto e meio dessas relações, as quais instrumentalizam um portfólio de tecnologias incorporadas no bojo do sistema de práticas sociais, em última instância, conformando estratégias refinadas de mobilização dos recursos naturais florestais e aquáticos que distinguem a região. Tais usos, nessa perspectiva, resultam de formas de conhecimento, associadas a valores e regras - instituições - que se revelam sob a forma de "trajetórias tecnológicas". Dentre essas, destacamse trajetórias camponesas, mobilizadas para resolver problemas produtivos e reprodutivos mediante, por um lado, uma racionalidade específica dominada por critérios da esfera reprodutiva, generalizável para economias camponesas em geral; por outro, formas particulares de ajustamento dessa racionalidade a condições materiais e institucionais próprias de lugares específicos - às formas territorializadas de existência camponesa.

Milton Santos (1996), em suas reflexões sobre o que chama de uma fenomenologia espacial, traz um entendimento da noção de território que, ao mesmo tempo que ressalta a dimensão espacial e seu substrato material, a natureza, portanto, como elemento-chave de compreensão da socialização dos indivíduos, sublinha que tal processo de construção social do espaço se faz pelo trabalho, como criador do vínculo social constitutivo que produz reconhecimento identitário, atrelando as pessoas à porção do espaço onde se reproduzem.

Nessas bases, se constitui a abordagem multidimensional que aqui será privilegiada, para a qual, em formulação ampla, o território é um híbrido da economia, da cultura e da política, com sua dimensão ambiental, ressaltam Saquet (2004, 2007) e Haesbaert (2004 p. 50).

Trata-se em última instância, retomando Santos (1996) para uma síntese, de dinâmica de poder em torno do uso de recursos tangíveis e intangíveis, gerando situações específicas onde eventos convergem na criação de realidade ímpar e dotada de possibilidades novas - na realidade, o espaço geográfico é sempre um campo de possibilidades (SANTOS, 1979), um produto das estratégias dos homens para produzir seus meios de existências, o que ocorre por meio do trabalho e o potencial criativo contido no seu exercício. 
Segundo Saquet (2007) a dimensão econômica é central do território, considerando este com enraizamento cultural, identidade, conexão societária, recursos naturais e as experiências do lugar de vida. Enfim, trata-se de síntese de processos - em sua articulação, processos de territorialização - que se dá por aspectos econômicos e culturais.

Autores como Raffestin (1993) ressaltam a dimensão material nas relações sociais constitutivas do território, destacando, entretanto, o caráter político dessas relações. A isso se refere Haesbaert (2007), quando enfatiza que o território nasce com a tomada de consciência dos homens sobre o significado do espaço como fundamento de poder. Nisso consistiria a dimensão subjetiva do território, relacionada a apropriação ou identidade territorial, que se verifica em unidade com uma dimensão objetiva em sentido concreto que se realiza por instrumentos de ação político-econômica (HAESBAERT; LIMONAD, 1999).

É como esforço de instrumentação de tais noções que compreendemos as indicações de economistas como Cristian Azaïs (2004), para quem trabalho e território são noções centrais em economia. Não obstante, adianta o autor, há dificuldades na articulação conceitual das duas esferas, o que se tem mostrado um desafio aos pesquisadores. Como contribuição à superação dessas dificuldades, o autor fornece um mapa possível de articulação, com a proposição de diferentes temporalidades operantes na noção de território-atores: as temporalidades sociais do trabalho, inscritas no curto prazo pelas premências reprodutivas imediatas, e as do território, expressando dinâmicas estruturais de tempo mais longo.

Este é, também, um ponto central na reflexão de Costa e Carvalho (2012), para quem a organização social do trabalho, não obstante, obedece em nível macro que é das regulações sistêmicas de um modo de produção dominante (o modo capitalista de produção como força hegemônica de última instância); em nível micro está condicionada por razões diversas, associadas a distintos atores e contextos. Assim sendo, em nível meso (onde se situam os territórios e sociedades locais), tal organização expressa essas diferentes razões em relação entre si na utilização das disponibilidades naturais, culturais e institucionais concretamente disponíveis (COSTA; CARVALHO, 2012).

Mobilizando tais supostos, Costa e Carvalho (2012) sugerem uma relação de dependência teórica estrita entre a categoria campesinato, de um lado com a categoria camponês e, de outro, com a categoria território. Nesse sentido, estes autores sugerem um modo de operar a proposição de Azaïs (2004), acima mencionada, de realçar as configurações relacionais território - atores como forma de superar as dificuldades de visão integrada entre economia e território. 
No Dicionário dos Movimentos Sociais no Campo, Costa e Carvalho (2012) definem de modo simples e direto o que seja campesinato como o conjunto de famílias camponesas existentes em um território. Parte da noção, todavia, é o conceito antes trabalhado por Costa e Carvalho (2012), de que:

Camponesas são aquelas famílias que tendo acesso à terra e aos recursos naturais que esta suporta, resolvem seus problemas reprodutivos - suas necessidades imediatas de consumo e o encaminhamento de projetos que permitam cumprir adequadamente um ciclo de vida da família - a partir da produção rural desenvolvida de tal maneira que não se diferencia o universo dos que decidem sobre a alocação do trabalho dos que se apropriam do resultado dessa alocação (COSTA; CARVALHO, 2012, p. 107).

E, ainda, que as famílias camponesas existem em territórios, isto é:

no contexto de relações sociais que se expressam nas regras de uso (instituições) das disponibilidades naturais (biomas e ecossistemas) e culturais (capacidades difusas internalizadas nas pessoas e aparatos infra-estruturais tangíveis e intangíveis) de um dado espaço geográfico politicamente delimitado (COSTA; CARVALHO, 2012, p. 28).

Em suma:

Unidades camponesas produzem orientadas pela finalidade comum da reprodução dos respectivos grupos familiares em perspectiva que incorpora consistência entre gerações - a geração operante se vê parte constitutiva das realizações de seus ascendentes e descendentes". Nisso se constitui sua especificidade, sua natureza essencial, a qual validam "[...] em combinações individualizadas de capacidades privadas, condicionadas por possibilidades e restrições das realidades locais, regionais e nacionais que findam por definir sua forma de existência. Nessa condição concreta constituem um campesinato (COSTA; CARVALHO, 2012, p.115).

\section{CAMPESINATOS AMAZÔNICOS E SEUS FUNDAMENTOS ESTRUTURAIS: AS TRAJETÓRIAS TECNOLÓGICAS}

Para entender a profunda diversidade estrutural da dinâmica rural na Amazônia, Costa (2010) utiliza a definição de Dosi (2006) de trajetória tecnológica e paradigma, e com base nela, diferencia, primeiro, as diferentes estruturas e razões camponesas e patronais; depois, apresenta as diferentes formas de evolução das estruturas camponesas expressas em diferentes trajetórias tecnológicas e faz o mesmo com as estruturas patronais.

Dosi define paradigma como "um modelo ou padrão de solução de problemas tecnológicos selecionados, baseado em princípios selecionados, 
derivados das ciências naturais e em tecnologias materiais selecionadas" (DOSI, 2006, p. 22-23). A solução para o problema tecnológico está no modo pelo qual os agentes econômicos operam sua produção e reprodução.

Dosi (2006, p. 22) define trajetórias tecnológicas como "um padrão usual de atividades, que resolvem com base em um paradigma tecnológico, os problemas produtivos e reprodutivos que confrontam processos decisórios de agentes concretos, em contextos específicos, nas dimensões econômica, institucional e social"

Assim é inserido o contexto ecológico (base natural) como determinante na estruturação de paradigmas e trajetórias tecnológicas para o agrário na Amazônia. Redimensiona o problema tecnológico ao tratá-lo como "problema na relação entre trabalho humano, objetivado por um modo de produção, e seu objeto último a natureza" (COSTA, 2010, p. 28). Ou seja, o padrão usual de como o agente opera seu objeto de trabalho, a natureza. Este modo de operação podese dar em dois paradigmas o agropecuário, cuja natureza é tratada como matériaprima, agregada aos processos produtivos e o paradigma agroextrativista, cuja natureza é considerada como capital natural, com capacidade produtiva tratada como valor de uso.

As soluções daí derivadas organizam as trajetórias tecnológicas entendidas por Costa (2009c, p. 229) como "a articulação processada por agentes orientados por racionalidades semelhantes, entre padrões produtivos e razões reprodutivas, expressas em heurísticas que se materializam em combinações particulares de meios e produtos."

Pautado na relação da diversidade de estruturas e agentes e em estatísticas disponíveis Costa (2009a) delimita para Amazônia trajetórias tecnológicas rurais, privilegiando as relações entre trajetórias e seus produtos.

De modo que observando, as características econômicas da produção, as interações que ocorrem entre os grupos de produtos e a distribuição espacial de sua ocorrência, a relação que apresentam com as instituições e a forma como se desenvolvem no tempo se espera configurar as trajetórias tecnológicas fundamentais na Amazônia (COSTA, 2009a, p.. 45).

O elemento que vai diferenciar uma trajetória da outra são as diversas formas técnicas utilizadas para combinar os meios produtivos, bem como a participação na divisão social do trabalho.

A diversidade de formas técnicas (combinação de meios) e de formas de participação na divisão social do trabalho (combinação de produtos) que diferencia as trajetórias depende das dotações naturais e institucionais que marcam as bases territoriais locais sobre as quais evoluem e dos nexos (que 
se conformam com a mediação destacada do mercado) que as vinculam a territorialidade mais amplas, nacional e mundial (cadeias de produção e troca) (COSTA, 2009a, p. 229).

Segundo Costa (2009b), uma trajetória tecnológica é um padrão usual de atividades que resolvem, com base em um paradigma tecnológico, os problemas (re) produtivo confrontando processos decisórios em contexto específico nas dimensões econômica, institucional e social.. Trata-se, assim, de noção capaz de operar a articulação entre as relações técnicas e sociais que configuram o território - como tal, este será visto como produto da reprodução de trajetórias em concorrência ou em cooperação.

Para a região Norte os atributos das diferentes trajetórias são comparados em acordo com sua relevância na economia regional, levando em consideração o Valor Bruto da Produção do setor Rural (VBPR), o que possibilitou ao autor a identificação de 6 trajetórias:

a) 'Trajetória Camponês.T1' reúne o conjunto de sistemas camponeses que convergem para sistemas com dominância de culturas permanentes e produção de leite. Marcada por uso intensivo do solo, com sistemas diversificados (baixo impacto na biodiversidade) e baixa formação de dejetos/impacto poluidor, explica 27\% do VBPR, 38\% do emprego, 10\% da área degradada e 11\% do balanço líquido de carbono. A economia em torno dessa trajetória cresce em termos absolutos a 5\% a.a., com rentabilidade crescente nos últimos tempos a 2,5\% a.a., por trabalhador a 4,3\% a.a. e por área a $0,3 \%$ a.a.

b) 'Trajetória Patronal.T4' reúne o conjunto de sistemas de produção em operação em estabelecimentos patronais que convergem para pecuária de corte. Marcada por uso extensivo do solo, homogeneização da paisagem (alto impacto na biodiversidade) e formação intensa de dejetos, explica 25\% do VBPR, 11\% do emprego, $70 \%$ da área degradada e $71 \%$ do balanço líquido de carbono. A economia em torno dessa trajetória cresce em termos absolutos a 5,1\% a.a., com rentabilidade crescente nos últimos tempos a 8,4\% a.a., por trabalhador a $9 \% \mathrm{e}$ por área a $6,2 \%$.

c) 'Trajetória Camponês. T2' reúne o conjunto de sistemas camponeses que convergem para sistemas agroflorestais com dominância ou forte presença de extração de produtos não-madeireiros. Explica 21\% do VBPR, 26\% do emprego, $3,5 \%$ da área degradada e 2,6\% do balanço líquido de carbono. A economia em torno dessa trajetória cresce em termos absolutos a 12\% a.a., com rentabilidade crescente nos últimos tempos, por trabalhador a $12,7 \%$ e por área a $11,4 \%$. Observe que seria uma trajetória expressão de um "paradigma agroflorestal" - 
no qual os processos produtivos, pressupõem, em algum nível, a preservação da natureza originária.

\section{O TERRITÓRIO DE PESQUISA}

O município de Mocajuba localiza-se à jusante da Usina Hidrelétrica de Tucuruí, na região do Baixo Tocantins, composta por mais de 10 municípios. A população que vive na área rural corresponde 52,79\% do total de 739.881 habitantes, destes 32.365 são agricultores familiares e 24.701 famílias assentadas (Plano Territorial de Desenvolvimento Rural Sustentável do Baixo Tocantins, de 2010), distribuídas em projetos agroextrativistas, terras indígenas e comunidades quilombola, e áreas das chamadas "colônias" ou "centros" - ocupações das áreas de terra firme.

Figura 1 - Mapa de localização do município de Mocajuba

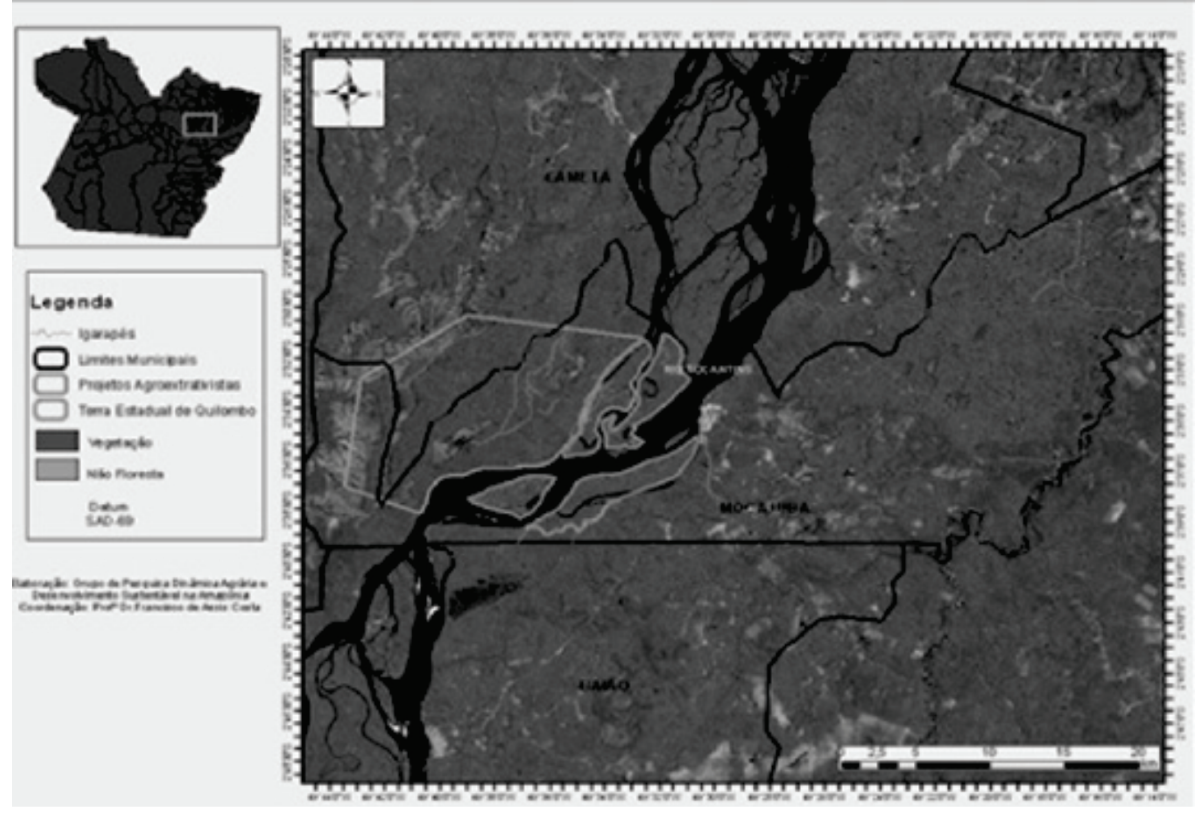

Fonte: GPDADESA/NAEA

A Terra Estadual de Quilombo do 2o Distrito de Porto Grande com 318 famílias (ITERPA, 2009) e os projetos de assentamento agroextrativista - Ilha Grande de Conceição de Mocajuba com 229 famílias; Ilha Grande do Vizeu com 204 famílias; Ilha de Angapijó com 36 e Tauaré com 187 famílias - englobam 17 comunidades legalmente reconhecidas. (Quadro 1). 
Quadro 1 - Comunidades presentes nos projetos de regularização fundiária em Mocajuba

\begin{tabular}{|l|l|}
\hline \multicolumn{1}{|c|}{ Projeto de regularização fundiária } & \multicolumn{1}{c|}{ Comunidades } \\
\hline TEQ- ${ }^{\circ}$ Distrito de Porto Grande & $\begin{array}{l}\text { Porto Grande, Mangabeira, São Benedito } \\
\text { do Vizeu, Santo Antônio do Vizeu, Uxizal, } \\
\text { Vizânia, Itabatinga }\end{array}$ \\
\hline PAE- Ilha Grande de Vizeu & Santo Antônio, Jacarecainha, Vizânia, \\
\hline PAE- Conceição de Mocajuba & Santana, São Joaquim, Costa de Santana \\
\hline PAE- Ilha Tauaré & Tauaré Grande, Tauarezinho \\
\hline PAE- Ilha Angapijó & Tatuoca, Angapijó \\
\hline
\end{tabular}

Fonte: Elaborado com base em informações do ITERPA e INCRA-SR 01 (2011)

As áreas que recentemente tornaram-se "assentamentos" em Mocajuba são dotadas de uma conotação geográfica/territorial, na qual a interação das comunidades com o meio revela uma dinâmica muito particular e reflete segundo Barbosa e Marin (2009) relações identitárias e os arranjos no uso do recurso disponível.

Pelos marcos legais temos uma situação peculiar para a compreensão das formas de uso do território na qual a dinâmica da paisagem revelada pelas análises de sensoriamento remoto apresenta baixa conversão da floresta a despeito da antiguidade dos processos de ocupação e formação histórico-territorial. Estas áreas correspondem a 44,3\% da área do município, e onde predominantemente encontram-se formas camponesas orientadas para o agroextrativismo.

Quadro 2 - Áreas de regularização fundiária em Mocajuba

\begin{tabular}{|l|c|c|c|c|}
\hline \multicolumn{1}{|c|}{ Local } & Área (ha) & Ato de criação & Capacidade & $\begin{array}{c}\text { Famílias } \\
\text { assentadas }\end{array}$ \\
\hline PAE Ilha de Angapijó & 996,451 & $186-15 / 12 / 09$ & 60 & 36 \\
\hline PAE Ilha C. de Mocajuba & $1.635,24$ & $187-15 / 12 / 09$ & 280 & 229 \\
\hline PAE Ilha Grande de Viseu & $1.497,77$ & $188-15 / 12 / 09$ & 260 & 204 \\
\hline PAE Ilha Tauaré & $2.174,87$ & $189-15 / 12 / 09$ & 250 & 187 \\
\hline TEQ - 2o Distrito & 17,220 & - & - & 318 \\
\hline
\end{tabular}

Fonte: Elaborado pelo autor com base em informações do INCRA-SR01 e ITERPA (2011)

Partimos do pressuposto que esse território de pequenos produtores familiares rurais é um território de mudanças, continuamente em movimento a partir dos seus processos de produção (trabalho). Os grupos constroem seus 
espaços de vivência com as técnicas que auxiliam no manejo dos elementos da natureza indispensáveis a sua sobrevivência, com isso organizam a produção e por conseguinte organizam a vida social e o espaço na medida de suas necessidades (SANTOS, 1996).

\section{A PESQUISA EM SEU NÍVEL MACRO: MOCAJUBA, OS CAMPONESES E SUAS TRAJETÓRIAS}

O município de Mocajuba apresenta características ainda mais estritas no que se refere à dominância de trajetórias camponesas: apenas duas delas se apresentam no município, a T1 e a T2. As duas trajetórias dividem bastante equilibradamente a economia rural do município, com predominância, porém da T2: 54\% do número de estabelecimentos, 59\% do emprego e do VBP. No quesito terra, porém, os estabelecimentos da T1 têm quase três vezes mais terra que os da T2: respectivamente, 53.113 e 18.879, 74\% e 26\% do total (ver Tabelas 1 e 2).

Tabela 1 - Setor rural de Mocajuba (MRH Cametá-PA), segundo o Censo de 2006

\begin{tabular}{|c|c|c|c|}
\hline & Camponês T1 & Camponês T2 & Total \\
\hline \multicolumn{4}{|c|}{ Valor da produção } \\
\hline VBP do extrativismo não-madeireiro & 240 & 334 & 574 \\
\hline VBP do extrativismo madeireiro & - & 1 & 1 \\
\hline VBP animal & 100 & 108 & 208 \\
\hline VBP culturas Permanentes & $4.993,00$ & $10.145,00$ & $15.138,00$ \\
\hline VBP culturas temporárias & $1.081,00$ & $3.363,00$ & $4.444,00$ \\
\hline VBP outros & $3.778,00$ & 572 & $4.350,00$ \\
\hline VBP total & $10.192,00$ & $14.523,00$ & $24.715,00$ \\
\hline Participação relativa & $41 \%$ & $59 \%$ & $100 \%$ \\
\hline
\end{tabular}

Uso da área dos estabelecimentos

\begin{tabular}{l|r|r|r}
\hline Área sistemas agroflorestais & 259 & 4.470 & 4.729 \\
\hline Área mata & 13.656 & 1.974 & 15.630 \\
\hline Área floresta plantada & - & - & - \\
\hline Área lavouras permanentes & 17.475 & 8.499 & 25.974 \\
\hline Área lavouras temporárias & 7.123 & 1.694 & 8.817 \\
\hline Áreas degradadas & - & 10 & 10 \\
\hline Outras & 14.600 & 2.232 & 16.832 \\
\hline Área total ha & 53.113 & 18.879 & 71.992 \\
\hline Participação relativa & $74 \%$ & $26 \%$ & $100 \%$ \\
\hline
\end{tabular}




\begin{tabular}{l|r|r|r}
\hline Tamanho médio da propriedade & 97,63 & 29,78 & 61,01 \\
\hline Número de estabelecimentos & 544 & 634 & 1.180 \\
\hline Participação relativa & $46 \%$ & $54 \%$ & $100 \%$ \\
\hline Pessoal ocupado & 1.179 & 1.668 & 2.846 \\
\hline Participação relativa & $41 \%$ & $59 \%$ & $100 \%$ \\
\hline \multicolumn{3}{c}{ Meta-função de produção dHaiamy-Hutan } \\
\hline VBP Total/pessoal ocupado = & $8.644,61$ & $8.706,83$ & $8.684,12$ \\
\hline VBP/Área total x & 191,89 & 769,27 & 343,3 \\
\hline Área/pessoal ocupado & 45 & 11,3 & 25,3 \\
\hline
\end{tabular}

Fonte: IBGE, Censo Agropecuário de (2006).

Os resultados econômicos principais são também equilibrados no que se refere à grandeza fundamental do trabalho aplicado, tal como a economia camponesa se regula (COSTA; CARVALHO, 2012): em valores correntes de 2006, o ano do Censo, a produtividade monetária do trabalho na T1 e na T2 foram, respectivamente, de $\mathrm{R} \$ 8.644,66$ e $\mathrm{R} \$ 8.706,83$.

Tabela 2 - Composição relativa do VBP e do uso da terra em Mocajuba no Censo de 2006

\begin{tabular}{l|r|r|r}
\hline & Camponês T1 & Camponês T2 & \multicolumn{1}{c}{ Total } \\
\hline \multicolumn{3}{|c|}{ Valor da produção } \\
\hline VBP do extrativismo não madeireiro & $2,40 \%$ & $2,30 \%$ & $2,30 \%$ \\
\hline VBP do extrativismo madeireiro & & $0,00 \%$ & $0,00 \%$ \\
\hline VBP animal & $1,00 \%$ & $0,70 \%$ & $0,80 \%$ \\
\hline VBP culturas permanentes & $49,00 \%$ & $69,90 \%$ & $61,30 \%$ \\
\hline VBP culturas temporárias & $10,60 \%$ & $23,20 \%$ & $18,00 \%$ \\
\hline VBP outros & $37,10 \%$ & $3,90 \%$ & $17,60 \%$ \\
\hline VBP total & $100,00 \%$ & $100,00 \%$ & $100,00 \%$ \\
\hline Participação relativa & $41 \%$ & $59 \%$ & $100 \%$ \\
\hline \multicolumn{1}{c|}{ Uso da área dos estabelecimentos } \\
\hline Área sistemas agroflorestais & $0,50 \%$ & $23,70 \%$ & $6,60 \%$ \\
\hline Área mata & $25,70 \%$ & $10,50 \%$ & $21,70 \%$ \\
\hline Área floresta plantada & & & \\
\hline Área lavouras permanentes & $32,90 \%$ & $45,00 \%$ & $36,10 \%$ \\
\hline Área lavouras temporárias & $13,40 \%$ & $9,00 \%$ & $12,20 \%$ \\
\hline Área degradadas & & $0,10 \%$ & $0,00 \%$ \\
\hline Outras & $27,50 \%$ & $11,80 \%$ & $23,40 \%$ \\
\hline
\end{tabular}

Fonte: IBGE, Censo Agropecuário de (2006). 
Esses valores equilibrados, todavia, resultam de fundamentos bastante desbalanceados. Sabemos que a produtividade por trabalhador (VBP/Pessoal ocupado) é igual a produtividade monetária da terra (VBP/Área) e do volume de terra por trabalhador (Área/Pessoal ocupado). A isso os economistas chamam de meta-função de produção de Hayami e Rutan (COSTA; CARVALHO, 2012). Pelos dados do Censo, portanto, as produtividades (monetárias) praticamente iguais da T1 e da T2 em Mocajuba se explicam por razões inversas: a produtividade monetária da terra é, para a primeira, $\mathrm{R} \$ 191,89$ e, para a segunda, $\mathrm{R} \$ 769,27$; a relação terra/trabalhador, por seu turno, na T1 é quatro vezes maior que na T2, respectivamente, 45,0 ha e 11,3 há (ver última parte da Tabela 3).

\section{6 ÁREAS DE TERRA FIRME E REGIÕES DE ILHAS: OS TERRITÓRIOS DA T1 E DA T2}

A pesquisa demonstrou claramente que as famílias camponesas das ilhas de Mocajuba são típicas da Trajetória T2. A Tabela 3 apresenta os resultados do valor da produção para as famílias pesquisadas, os quais não deixam lugar a dúvidas: suas unidades produtivas são baseadas em um perfil da produção completamente compatível com a expectativa em relação a essa trajetória.

A relevância das lavouras permanentes (35,2\% do VBP do conjunto de familias pesquisadas), da pesca (28,8\% do mesmo total) e da extração nãomadeireira (15,2\%), indica se tratar de produção baseada em SAF, típicas da T1 (ver Tabelas 1, 2 e 3). Isto nos permite afirmar ser a região das ilhas de Mocajuba um território da T2. Cabe dizer, em complemento, que, como se pode avaliar no Anexo 1, onde se esclarece o plano amostral da pesquisa, a amostra é suficiente para expressar o universo, considerando os dados do Censo para a trajetória e da base considerada para a população de várzea na amostra; respectivamente, 634 (ver Tabela 3). Não é o caso da amostra relativa às famílias do ambiente de terra firme, insuficiente para garantir inferência estatística, uma vez que se considerou, para o cálculo da amostra, 318 unidades familiares (baseados nas listas de assentamento que se dispunha), quando o universo apresentado no Censo seria de 544 unidades familiares. Não se recorrerá a ela, portanto. Não se precisaria dela, na verdade, para concluir o que importa: se está suficientemente demonstrado que as ilhas de Mocajuba constituem o território da T2, a T1 se assenta, seguramente, nas áreas de terra firme.

Isto posto, vale discernir as consequências do achado, detalhando as características dos dois padrões territoriais indicados e associando-os aos padrões produtivos das duas trajetórias. Nisso, torna-se fundamental trazer para 
a discussão as indicações territoriais resultantes das análises combiná-las com os dados já apresentados da Tabela 3.

Tabela 3 - Valor Bruto da Produção (VBP) das famílias pesquisadas nos ambientes das ilhas e de terra firme em Mocajuba

\begin{tabular}{l|r|r}
\hline \multicolumn{1}{c|}{ Atividades } & \multicolumn{1}{c|}{ VBP } & \multicolumn{1}{c}{$\%$} \\
\hline Alimentação pequenos animais & $1.267,05$ & $2,00 \%$ \\
\hline Artesanato de artefatos & 384,3 & $0,60 \%$ \\
\hline Artesanato de produtos & 264,84 & $0,40 \%$ \\
\hline Caça & 90 & $0,10 \%$ \\
\hline Comercialização & $7.312,19$ & $11,70 \%$ \\
\hline Extração madeireira & 629,9 & $1,00 \%$ \\
\hline Extração não madeireira & $9.499,54$ & $15,20 \%$ \\
\hline Fabrico & 613,9 & $0,10 \%$ \\
\hline Lavoura permanente & $22.033,61$ & $35,30 \%$ \\
\hline Lavoura temporária & 506,19 & $0,80 \%$ \\
\hline Pesca & $17.957,57$ & $28,80 \%$ \\
\hline Trabalho externo & $1.800,00$ & $2,90 \%$ \\
\hline Total & $62.358,47$ & $100,00 \%$ \\
\hline
\end{tabular}

Fonte: Pesquisa de Campo do GPDadesaNAEA.

São os seguintes os pontos importantes:

Na paisagem, a área detectável como ligada à produção rural é, no território da T1, 31\% da área passível de se tornar, por critério privados, em áreas com tal destinação; no território da T2 essa proporção é 1/3 menor - 10,4\%.

A distribuição dos usos na produção rural difere, também: enquanto na T2 praticamente se explica por culturas permanentes e SAF, no território da T1 há presença com algum significado de diferentes formas de pasto, bem como de roça.

Em 2012 não se constatou desmatamento no território da T2 e, não obstante existir, o que se verifica para a T1 se aproxima da irrelevância.

O território da T2 apresenta $67,1 \%$ coberto por vegetação originária (floresta e campinarana), enquanto o da T1 36,4\%;

Se se consideram formas de intermediárias de bosque florestal, isto é, florestas originárias (provavelmente) sobre-exploradas (que o TerraClass classifica como Floresta degradada) e, na direção inversa, áreas antes agricultadas hoje em regeneração avançada (capoeiras), tem-se, nessa condição, 16,5\% no território da T2 e 25,8\% no território da T1. 
Se se compõe os dois itens anteriores, chegando a um agregado de formas florestais e outras vegetações originais não florestais, no território da T2 elas cobrem 89,5\%, enquanto que no da T1 elas chegam a 62,2\%.

Por fim, um resultado importante para este trabalho: o território da T1 teve $92,4 \%$ da área apropriável para a produção rural (a área total do território menos áreas urbanas e mananciais de água) declarada no Censo Agropecuário como propriedade ou domínio de alguém presente no território, uma vez que respondeu à entrevista do IBGE. Isso já era esperado para essa trajetória. Surpreendente é o fato de que a proporção para o território da T2 não é muito diferente: nada menos que $89,1 \%$ da área foi declarada como de domínio privado no Censo.

Os seis primeiros pontos listados apresentam as diferenças objetivas nos padrões territoriais indicados antes - e corroboram com a hipótese de que as trajetórias conformam, sim, às respectivas imagens, de modos bem distintos, seus territórios. O último, a sua vez, contraria nossa expectativa de que as grandes diferenças se explicariam pela presença de "recursos comuns" em territórios dominados pela T2, implicando em soluções de acesso e uso preservadores. Se assim fosse, a eficiência que se verificou na produtividade monetária da terra agregada para a trajetória, como se viu no censo, deveria ser resultado da não consideração (contabilização) das terras onde deveriam se encontrar os "recursos comuns", que nessa condição não encontram abrigo na lógica baseada em estabelecimentos do Censo.

As técnicas utilizadas combinam conhecimento do comportamento da fauna silvestre, do clima regional e técnicas de manejo do solo. As práticas sócio-culturais, bem como a gestão do território pela T2 enquanto, sistemas de manejo local, configuram as técnicas identificadas a partir de trabalho de campo, estas divididas em três grandes conjuntos: a) as agrícolas ligadas ao uso do solo, essencialmente; as técnicas agro-florestais; técnicas de uso de recursos aquáticos e/ou pesqueiros que subdividem-se em técnicas de pesca de camarão e pequenos mariscos; e as técnicas de pesca de peixes e aquicultura;

As técnicas agrícolas usadas na exploração das Florestas Ombrófilas densas de terras baixas para a produção de farinhas e processamento de derivados da mandioca, conhecidos como "roças", são pautados no uso do corte e queima relevam a forma mais expressiva quanto a conversão de áreas de florestas em áreas antropizadas. No entanto, o sistema de pousio, herança indígena, leva a processos de regeneração das florestas originando grandes áreas de florestas primárias.

Juntos os percentuais de Floresta Secundária, Floresta Ombrófila Densa de Terras Baixas, Floresta Ombrófila Densa Aluvial e Floresta Ombrófila Densa Aluvial com Dorsel Emergente somam 44,3\% de áreas ocupadas por cobertura 
vegetal para o município de Mocajuba. Os índices sugerem maior nível de conservação nas áreas de ocupação da T2, se comparados aos 22,9\% de culturas cíclicas e permanentes encontrados na margem direita do rio Tocantins onde se localiza a sede municipal com maior concentração populacional e predominância da trajetória T1

Nas tabelas abaixo têm-se demonstrado os percentuais correspondente aos tipos de uso por área territorial, primeiro para o município e em seguida para áreas com predomínio das trajetórias camponesas T1 e T2, respectivamente.

O mapeamento do projeto Terraclass, reforça mais ainda o nível de preservação natural das áreas de ilhas, onde se concentrou a pesquisa, mostrando que depois da vegetação secundária, considerada um estágio sucessional de desenvolvimento, a classe predominante é de Floresta com aproximadamente 15,67\% de área estimada para o município, seguida de mosaico de ocupações com 19,39\% representados por estes pequenos camponeses que diversificam sua produção e conseguem com métodos específicos de manejo a manutenção de altos níveis florestais, o que nos leva a crer mais condizentes com o ideal de sustentabilidade. Ao analisarmos a territorialidade expressa em trajetórias, temos os seguintes resultados de área $(\mathrm{km})$ encontrados para o território da T1 (Tabela 4):

Tabela 4 - Classes de uso e cobertura da terra na área da T1

\begin{tabular}{l|r|r}
\hline Classes de uso e cobertura da terra & Área $\left(\mathrm{km}^{2}\right)$ & Área $(\%)$ \\
\hline Área não observada & 0,77 & $0 \%$ \\
\hline Área urbana & 5,22 & $1 \%$ \\
\hline Desflorestamento 2012 & 0,23 & $0 \%$ \\
\hline Floresta & 34,30 & $6 \%$ \\
\hline Hidrografia & 2,50 & $0 \%$ \\
\hline Mosaico de ocupações & 87,46 & $17 \%$ \\
\hline Não floresta & 102,10 & $19 \%$ \\
\hline Outros & 2,92 & $1 \%$ \\
\hline Pasto limpo & 19,37 & $4 \%$ \\
\hline Pasto sujo & 4,31 & $1 \%$ \\
\hline Regeneração com pasto & 0,67 & $0 \%$ \\
\hline Vegetação secundária & 269,97 & $51 \%$ \\
\hline Total & 529,04 & $100 \%$ \\
\hline
\end{tabular}

Fonte: Terraclass (2012)

Ao correlacionar a territorialidade da T1 com a área total, temos mosaico de ocupação com 10,05\%, seguido de pasto limpo com 2,22\%, como as mais expressivas formas de uso da terra na porção oeste do município, onde se deu 
grande parte de sua ocupação e se estabeleceu a trajetória que convertia para o plantio de pimenta-do-reino, e atualmente com a introdução de novos vetores produtivos com destaca-se, fortemente, o plantio de dendê (Elaeis guineenses). Para as classes de cobertura vegetal a vegetação secundária corresponde a pouco mais de 31\% do total, enquanto que as áreas de floresta a 3,94\% de área. Já para a trajetória T2 que se concentra espacialmente à margem esquerda do rio Tocantins foram encontrados as seguintes áreas:

Tabela 5 - Classes de uso e cobertura da terra na área da T2

\begin{tabular}{l|r|r}
\hline Classes de uso e cobertura da terra & Área $\left(\mathrm{km}^{2}\right)$ & Área $(\%)$ \\
\hline Área não observada & & $0 \%$ \\
\hline Desflorestamento 2012 & 0,09 & $0 \%$ \\
\hline Floresta & 102,13 & $30 \%$ \\
\hline Hidrografia & 73,50 & $22 \%$ \\
\hline Mosaico de ocupações & 10,75 & $3 \%$ \\
\hline Não floresta & 66,93 & $20 \%$ \\
\hline Outros & 0,07 & $0 \%$ \\
\hline Pasto limpo & 0,17 & $0 \%$ \\
\hline Pasto sujo & & $0 \%$ \\
\hline Regeneração com pasto & & $0 \%$ \\
\hline Vegetação secundária & 86,46 & $25 \%$ \\
\hline Total & 340,09 & $100 \%$ \\
\hline
\end{tabular}

Fonte: Terraclass (2012)

Observa-se com isso que as classes de cobertura vegetal mais expressivas no território da T2 em Mocajuba são Floresta e Vegetação secundária, respectivamente com 11\% e 9\% correspondentes ao percentual total de área, em contrapartida as a única classe de uso da terra que identificada é a classe mosaico de ocupações com 1,23\% de ocupação de área. Ao analisar os proporcionais de área para as duas trajetórias espacializadas, observa-se para o território de T2 usos como regeneração com pasto, pasto sujo e pasto limpo são pouco sem nenhuma expressão, tais formas de manejos do bioma usos atribuídos a áreas que já foram anteriormente desmatadas para alguma finalidade, no caso da T1 o que nos leva a crer, áreas usadas para o plantio de pimenta, e atualmente do dendê, que requer grandes extensões de área para plantio, por outro lado, a forte presença de classe como regeneração com pasto, pasto limpo e pasto sujo no território da T1 responde por quase $25 \mathrm{~km}^{2}$ de área. Enquanto que no território da T2 juntas as áreas de floresta e vegetação secundária, respondem por 188,54 $\mathrm{km}^{2}$ de área. 


\section{CONSIDERAÇÕES FINAIS}

A trajetória T2 configura o território em que atua, com base no processo de trabalho, resultante de formas de operacionalização específicas do bioma amazônico. Orientandos por uma lógica, que tem como fundamento primordial a racionalidade camponesa, baseada na eficiência de seus padrões (re)produtivos, que agregam capacidades de uso sustentável do bioma, o que em última instância revela uma forma de gestão territorial mais correspondente aos pressupostos da sustentabilidade.

Pode-se afirmar ainda que o trabalho é parâmetro fundamental de alocação espacial, por expressar-se em extensão, mobilidade e padrões de alocação, bem como o território, que neste contexto torna-se o atributo essencial de fundamentação do trabalho. O que reforça a ideia de que trabalho e território são categorias analíticas centrais para a economia e que em conjunto, tornam-se chave de interpretação dos processos de socialização dos indivíduos, que dão, em última análise, sob bases espaciais.

\section{REFERÊNCIAS}

ALLIĖS, P. L'invention du territoire. Grenoble: PUG, 1980.

AZAÏS, C. Território e trabalho: uma inscrição em temporalidades diferentes. Novos Cadernos NAEA, Belém, v. 7, n. 1, p. 31-56, jun. 2004.

BELLET, M.; COLLETIS, G.; YUNG, Y. Introduction au numéro spécial Économie de Proximités. RERU, [S.1.], n. 3, 1993.

BERTHELOT, J-M. Sciences sociales, temps et espace. In: OSTROWETSKY, S. (Ed.). Sociologues en ville. Paris: L'Harmattan, 1996. p. 65-70.

COSTA, F. de A. Heterogeneidade estrutural e trajetórias tecnológicas na produção rural da Amazônia: delineamentos para orientar políticas de desenvolvimento. In: BATISTELLA, M.; MORAN, E.; ALVES, D. S. (Org.). Amazônia: natureza e sociedade em transformação. São Paulo: EDUSP, 2008. 304 p.

Desenvolvimento agrário sustentável na Amazônia: trajetórias tecnológicas, estrutura fundiária e institucionalidade. In: BECKER, B.; COSTA, F. A.; COSTA, W. M. Desafios ao Projeto Amazônia. Brasília, DF: CGEE, 2009a. p. 215-363.

Trajetórias tecnológicas como objeto de política de conhecimento para a Amazônia: uma metodologia de delineamento. Revista Brasileira de Inovação, v. 8 , n. 1, p. 35-86, jan./jun. 2009b. 
Dinâmica agrária e balanço de carbono na Amazônia. Economia, v. 10, n. 1, p. 117-151, jan./mar. 2009c.

Mercado e produção de terras na Amazônia: avaliação referida a trajetórias tecnológicas. Boletim do Museu Paraense Emilio Goeldi. Ciências Humanas, Belém, v. 5, p. 25-39, 2010.

COSTA, F. de A; CARVALHO, H. de. Campesinato. In: CALDART, R. S.; PEREIRA, I. B. et al. (Org.). Dicionário de Educação no campo. Rio de Janeiro, São Paulo: Escola Politécnica de Saúde Joaquim Venâncio, Expressão Popular, 2012. p. 45

DOSI, G. Technological paradigms and technological trajectories. Revista Brasileira de Inovação, v. 5, n. 1, p. 17-32, jan./jun. 2006.

HAESBAERT, R. O mito da desterritorialização: do "fim dos territórios" à multiterritorialidade. Rio de Janeiro: Bertrand Brasil, 2004.

HAESBAERT, R.; LIMONAD, E. O território em tempos de globalização. GeoUERJ. Revista do Departamento de Geografia, Rio de Janeiro, UERJ, n. 5, p. 7-19, 1999.

KRUGMAN, P. Space: the final frontier. Journal of Economic Perspectives, [S.1.], v. 12, n. 2, p. 161-174, 1998.

PRÉVÔT SCHAPIRA, M-F. Territoires, pouvoirs et sociétés em Amérique latine. Tours: Université de Tours François Rabelais, UFR de Droit, d'Economie et des Sciences Sociales, 1997. Rapport d'habilitation à diriger des recherches, document ronéo.

RAFFESTIN, C. Por uma geografia do poder. São Paulo: Ática, 1993.

SANTOS, M. A natureza do espaço. Técnica e tempo, razão e emoção. São Paulo: Hucitec, 1996.

O espaço dividido. São Paulo: Francisco Alves, 1979.

SAQUET, M. A. Abordagens e concepções de território. [S.1.]: Expressão Popular, 2007.

O território: diferentes interpretações na literatura italiana. In: RIBAS, A. D.; SPOSITO, E. S.; SAQUET, M. A. Território e desenvolvimento: diferentes abordagens. Francisco Beltrão-PR: Unioeste, 2004, p. 87. 
